\section{How to Make "What Works" Work: A Role for the Resource Teacher Learning and Behaviour}

\author{
CHARLOTTE THOMSON
}

\section{Abstract:}

This article identifies the need for New Zealand schools to implement empirically-based research strategies in order to improve achievement outcomes for students whose needs they are failing to meet. The article highlights the gap between research and practice, and the construct of acceptability is examined as a possible explanation for the gap. Variables affecting the acceptability of interventions are analysed under three headings - the intervention, the teacher and the support needed to bring about change. Finally, the paper makes a case for the suitability of the Resource Teachers Learning and Behaviour (RTLB) to fill the role of a scientist-practitioner in order to link the theoretical positions of the academic researcher and the teacher at the front line.

he Tomorrow's Schools reforms (Department of Education, 1988), although primarily motivated by a political desire to change the administration of New Zealand's education system, contained policy imperatives for schools to ensure that all pupils achieved academically and socially. The policy reform documents, their several revisions, and subsequent special education policy (Ministry of Education, 1993, 1996, 1997) established an official position of equitable rights for all students. They recognized the uniqueness and diversity of individual students and the impact of environmental factors such as quality of teaching, administration structures and teacher behaviour on student achievement (Thomson, Brown, Jones \& Manins, 2000). Schools were mandated to find out the particular needs of individual students and groups of students, to identify the barriers to learning for these students, and to implement strategies to overcome these barriers.
Thus the underpinning philosophy, whether intentional or not, is firmly grounded in an interactive, inclusive/ecological paradigm where student functioning is conceptualized as an interaction between the unique characteristics and needs of the student and the facilitating or detrimental elements of the educational environment. Within this approach, schools are seen to contribute to, and more importantly, to have the potential to alter, the performance of their students (Stoiber \& Kratochwill, 2000). Schools thus are seen to be accountable for students' poor performance as well as their successes.

Despite these policy requirements for ensuring high levels of achievement for all, the evidence suggests that our schools are failing an unacceptable number of students. Reports comparing international standards of achievement (OECD, 2001; UNICEF, 2002) indicate that New Zealand has a high average level of achievement in reading and mathematics, but has a huge gap between the average score and the bottom 5 percent. This ranking indicates the level to which a country is willing to allow its weakest students to fall. On this scale, New Zealand is placed 23rd of the 24 OECD nations. Ministry of Education data have shown consistently that many students leave school with no qualifications. Maori and Pasifica students are significantly overrepresented in that group (Ministry of Education, 2004).

The reports clearly indicate that the needs of a large number of New Zealand students are not being met. The international statistics could be seen as a wake-up call for educators to review the teaching strategies employed in our schools and to plan to develop and implement strategies that have been shown empirically to be effective for students who are not achieving.

\section{The Research/Practice Gap}

The purpose of empirically supported interventions is to ensure improvement in student outcomes. The emphasis in recent reforms in education internationally on accountability and outcomes-based activities has encouraged a research interest in this area. Internationally, empirically-based information about effective interventions is readily available, and has been available for some time. (Gersten, Vaughn, Deshler \& Schiller, 1997; Stanovich \& Stanovich, 1997). Over fifteen years ago the United States Department of Education conducted a major study to provide information on "What Works" from the research literature on teaching and learning (United 
States Department of Education, cited in Stoiber \& Kratochwill, 2000). A number of meta-analyses have been conducted since that time, documenting well-researched, empirically-based practices (Forness, Kavale, Blum \& Lloyd, 1997; Swanson, 2001). Recently, Alton-Lee (2003) has reviewed the literature on effective interventions, for the New Zealand Ministry of Education. There is no dearth of evidence in the literature concerning effective interventions for ensuring success for students who are not achieving.

It appears, however, that practitioners' enthusiasm for researchbased practices is limited. There is a gap between education research and classroom practice (Carnine, 1995; Fullan, 1991; Gersten et al.,1997; Ysseldyke, 2001). "Research findings in education, as in other fields (e.g., health), are embraced by some, ignored by others and modified to suit the routines and preferences of still others" (Gersten et al., p. 466). Even when practices are shown unequivocally to produce positive outcomes for students, sustained use by practitioners is not guaranteed. Reflecting on his 25 years as an educational researcher, Ysseldyke (2001) identifies teachers' unwillingness to put into practice well-researched methods as a phenomenon encountered early in his research career. He identifies monitoring student progress as a case in point. Despite overwhelming evidence that this practice improves outcomes for students, teachers have not incorporated it into their basic repertoire of skills. "Even when they are confronted with evidence that what they are doing doesn't work, people keep on doing it. Even when other procedures are shown to be demonstrably better, people keep on doing the same old things" (p. 296).

On the other hand, practitioners often enthusiastically adopt methods with minimal or dubious research bases. Dewey (cited in Shulman, 1998) expressed his concern that teachers in his own day were "far too susceptible to passing fads and lofty rhetoric" (p. 514). Stanovich and Stanovich (1997) identified facilitated communication, a method to help children with autism communicate through intermediaries using typewriters, as one example of a practice widely adopted by practitioners (and enthusiastically received in the media) for a number of years, despite controlled studies having "unequivocally demonstrated that the performance of the child with autism is dependent on tactile cuing from the facilitator" (p. 478). They point out that interventions that lack an empirical base are not "benignly neutral". This was the case with facilitated communication, for example, which led to false hope for parents. The use of learning styles is another case in point, particularly in New Zealand. Learning styles have widespread currency in New Zealand schools and classrooms, yet there is no empirically supporting data base (Stahl, 1999). This methodology has even been officially sanctioned by such institutions as the Ministry of Education (1994) and Education Review Office (1998). Realistically, teachers cannot look to administrators for leadership in this area. As Stoiber and Kratochwill (2000) point out, "The intuitive appeal of a procedure appears to be more convincing for some school based practitioners than does empirical evaluation" (p.81)

There appears to be a growing awareness, however, that "we know considerably more about effective instruction than is typically represented and maintained over time in classrooms" (Vaughn, Klinger \& Hughes, 2000). Essential questions that need to be addressed are: Why are empirically based procedures not implemented widely? What can be done to improve the likelihood of their adoption? (Gersten et al., 1997; Wong, 1997). Clearly it is not enough to know "what works" in a controlled research environment. It is necessary to know how to make "what works" work in the complex reality of the classroom. A key variable and stakeholder in that complex reality is, of course, the classroom teacher.

Vaughn et al. (2000) warn against the tendency to blame the teacher, and counsel against using the simplistic explanation that some teachers choose to continue to use approaches they know and are comfortable with and that are easy for them to implement. Nor, they argue, should we blame the researcher - the impact of educational research has not been as significant as it might have been because most researchers do not understand the mind-set of teachers, and design interventions that do not adequately reflect the realities of classroom teachers (Gersten et al., 1997; Malouf \& Schiller, 1995; Wong, 1997). There is validity in both of these positions, but if progress is to be made we must move from blaming to understanding, to identify why teachers behave as they do, and that is going to be as complex as any human motivational issue. We must explore the nature of the communication between two groups of people with quite different mindsets and paradigmatic approaches, and that is going to be as complex as any human communication issue. Clearly it is an area that is not going to respond readily to "silver bullet" or "quick fix" solutions. 


\section{Intervention Acceptability : The Construct}

Understanding why, when and how research practices are implemented and sustained by teachers has come to be known as intervention acceptability. Recently there has been growing interest in the topic (Elliott, Witt \& Kratochwill, 1991; Gresham \& Lopez, 1996). The importance of the construct is self-evident - if an intervention is unacceptable to the teacher, it is unlikely to be implemented and will not benefit anyone. It is therefore important to find ways of increasing the likelihood that an intervention will be used and implemented with integrity. "A need exists for an assessment of the acceptability, as well as the effectiveness of interventions" (Elliott \& Darveaux, 1985).

The construct is a complex one and incorporates elements of social validity and consumer satisfaction. Much of the work on intervention acceptability done in the behavioural field has been analogue research and its validity regarding generalization to actual practice has been questioned (Kratochwill \& Stoiber, 2000). In some ways this analogue research itself represents some of the difficulties with academic research. It is conducted in a way which is divorced from the real life situation of the classroom; teachers are asked to respond to standard vignettes prepared by the researchers, but there is no way of knowing how big the gap is between what the teachers say they will do and what they might actually do in practice. However, this article does not rely only on the behavioural acceptability research, but draws on a range of sources that are not always brought together in the examination of intervention acceptability. Pertinent information comes from many disciplines, including research in change, restructuring and reform, consultation, professional development, teaching, reflective practice, as well as implementation of behavioural interventions. Synthesis is therefore not straightforward (Gersten \& Brengelman, 1996).

Wolf's work on social validity (Wolf, 1978) forms the conceptual foundation for intervention acceptability research (Eckert \& Hintze, 2000). Social validity refers to the social desirability, usefulness and importance of interventions, and addresses the value of behaviour change interventions within the context of the broader social environment. It provides a conceptual framework for evaluating and validating interventions within a social context. Wolf conceptualized social validity as encompassing: (a) the social significance of the goals; (b) the social appropriateness of the procedures; and (c) the social importance of the effects. Kazdin (1981) further developed Wolf's concept and identified intervention acceptability as one critical component of the social validity construct, defining it as "judgments by laypersons, clients and others of whether treatment procedures are appropriate, fair and reasonable for the problem or client" (p. 493). Much of the early work in the area emanated from a behavioural perspective but has subsequently been developed by workers in other fields. Witt and Elliott's (1985) definition reflects that of Kazdin, "Acceptability, in its most rudimentary form consists of judgments from treatment consumers pertaining to whether or not they like the treatment procedures or effects. In other words, it is the subjective evaluation of an individual's satisfaction with treatment" (p. 254).

Thus, acceptability has been operationalised as referring to consumers' judgments, focusing on their perspectives, opinions and satisfaction levels. Any attempts to increase the chances of the implementation of interventions will therefore involve the examination and manipulation of the variables that influence those perspectives and judgments.

\section{Intervention Acceptability: The Variables}

By synthesizing the data from a range of research areas it is possible to identify a number of variables that can influence the acceptability of interventions. Given the complexity of the construct it is possible to categorize these variables in a number of different ways. In this article they will be examined under the framework of the intervention, the teacher, and the support structures. What are we asking the teacher to do? What personal and professional factors contribute to motivating the teacher? What is the nature of the support structures required to maximize that motivation? These have been separated for convenience and ease of examination but are, of course, interlinked.

\section{The intervention}

"An intervention derived from research must penetrate the welter of practice at the local level, work its way into the crowded agenda of the local practitioner and find meaningful implementation in the classroom" (Malouf \& Schiller, 1995, p. 423).

According to Gersten et al. (1997), the first lesson "learned - and relearned" (p. 468), is what they refer to as the reality principle. However effective interventions may be in strictly controlled research 
situations, unless they are adapted to meet the realities and suit the ecology of the classroom, teachers will not implement them (Deshler \& Schumacher, 1994; Detrich, 1999; Lenz, Allen \& Ehrhardt, 1996; Malouf \& Schiller,1995; Pressley \& El-Dinary, 1997; Vaughn et al., 2000). Interventions which ensure minimum disruption to the ongoing classroom activities and which take heed of the demands (time, curricular and administrative) made on the teacher are likely to viewed more favourably by teachers. Feasibility is important.

Interventions that are aimed exclusively at meeting the needs of a particular student are likely to be ignored (Gersten et al, 1997; Schumm et al.,1995; Scott, Vitale, \& Masten, 1998). Schumm found that while teachers claimed they were willing to make adaptations for students with special needs they were only willing to do so if those adaptations were perceived as being effective for typical students as well. Thus strategies such as reciprocal teaching and class-wide peer tutoring are much more likely to be accepted and sustained by classroom teachers than, for example, direct instruction or precision teaching, which are much more focused on an individual student.

Classrooms cultures vary - culture being used here in its broadest sense of referring to shared social and behavioural norms. To be acceptable to teachers, interventions need to be classroom-culture specific, focusing on competencies that have validity within that culture. One of the realities of today's classrooms is the diversity of the student population. Interventions need to be designed for a much greater range of ethnic, socioeconomic and cultural groups than previously. Understanding the classroom culture or ecology is considered critical to the development of culture specific, ecologically valid interventions that are acceptable to the teacher (Nastasi, Varjas, Schensul, \& Silva, 2000)

Interventions that are complex and time consuming are not likely to be implemented by teachers (Gresham, 1989; Elliott \& Darveaux 1985; Lenz, Allen \& Ehrhardt, 1996; Elliott et al., 1991; Telzrow \& Beebe, 2002). The research results that demonstrate these as factors should come as no surprise. Time is "a universally valued commodity among teachers. Anecdotally, perhaps the most frequent reason given by teachers for not implementing a consultation plan is lack of time" (Gresham, 1989, p. 39). Obviously, interventions that take up too much time do not take into account the demands on the teacher and the disruption to the routines of the classroom.
The scope and the magnitude of change required by the interventions has only recently been a topic of study. Teachers, on the whole, regard their own practices as, at least, moderately effective. Change is more likely to be sustainable if the interventions require teachers to enhance, develop and refine their present practices rather than radically change their procedures or substitute entirely new ones (Detrich, 1999; Gersten et al., 1997; Pressley \& El-Dinary, 1997).

Much of the work on empirically supported interventions has been done within a functional deficits, within-child paradigm where, philosophically and administratively, categorization is the norm. This work has not typically taken into account the contextual influences on student difficulties (Kratochwill \& Stoiber, 2000). "Any system that targets pathology within the individual may miss important ecological variables ... and thereby misdirect the intervention focus away from the environmental context" (p. 241).

Interventions for broad-based categories of student problems such as emotional or behavioural disturbance, learning disabilities or cognitive disability do not give enough guidance to a teacher to let them know what to do with this child in this particular situation. Lenz and Daly (1996) sum up the situation succinctly: "Interveners propose, the ecology disposes" (p. 341)

\section{The teacher}

As Malouf and Schiller (1995) aptly point out, "The process of applying research in ... education can never be better than the local practitioner is able to make it. And the ultimate agent of innovation ... will always be the teacher who faces the class each morning" (p. 172). Not only teacher knowledge and skill, but also teacher attitudes and beliefs are inevitably going to impact greatly on whether and which researchbased practices will be implemented.

There has traditionally been a tendency to view teacher knowledge and practice as consisting of discrete elements such as "competencies" or "dispositions" that can be validated and appraised and added incrementally to their teaching. Yet, more recent conceptions of learning view it not as an additive process but a developmental process, in which new knowledge is assimilated into existing knowledge structures, possibly changing the structures in the process (Malouf \& Schiller, 1995; Richardson, 1990). The role of prior knowledge is therefore crucial. Teachers cannot implement practices 
if they do not have the pre-requisite knowledge or skills to do so. To initiate new practices, teachers are required to weave new knowledge from research into their existing knowledge. They need first to understand the new knowledge before they can use it. It may be necessary to scaffold the teacher into the new knowledge and understanding. In Vygotskyan terms, the new knowledge has to be within the teacher's zone of proximal development. Teachers need the opportunity to discuss new practices, to call into question their present practices and be free to accept, reject or modify innovations in accordance to their adequacy in their own situation.

Attitudes and beliefs are closely related to knowledge, although there is disagreement about the nature of the relationship (Pajares, cited in Malouf \& Schiller, 1995). "Although attitudes and beliefs are relatively difficult to define and study, they are thought to influence practice and must therefore be included in any serious consideration of practice and its improvement" (Malouf \& Schiller, 1995, p. 418). All of us, including teachers, sift new information through the lens of existing knowledge, conceptual and professional biases and values and attitudes before assimilating it. Thus, attitudes and values shape existing thought. Attitudes are resistant but not impervious to change.

Perhaps one of the most important attitudes of teachers and a critical variable in the implementation of new practices is their judgment of their own ability to have a positive impact on students. This is known as their sense of self-efficacy, and has been found to be a factor in whether teachers adopted and sustained new practices (Wong, 1997). Sparks (cited in Wong) found that teachers with a high sense of self-efficacy were more willing to experiment with a new teaching approach. Those with poor self-efficacy were found to be defensive of their teaching practices, made few instructional changes and had lower expectations for themselves and their students. "We cannot reach the point of getting teachers to value empiricallyvalidated teaching approaches if they do not have sufficient self-efficacy to risk trying them out" (Wong, p. 483). Consequently building self-efficacy in teachers would appear to be a priority in bringing about changes in teaching practice.

One issue of concern identified by Malouf and Schiller (1995) is the negative attitude towards research held by many teachers. Teachers view research as too removed from the classroom and irrelevant. They are often much more interested and willing to implement what the teacher down the corridor had success with last week than anything written in an academic journal. Anti-science and anti-ivory tower feelings are not hard to find in the teaching profession. Educational research and training institutions are often viewed as divorced from "the real world".

One way to address negativity toward research may be to provide teachers with more knowledge and appreciation of the scientific process (Stanovich \& Stanovich,1997). At the very least, teachers need a way of evaluating the credibility of the latest fad and flavour-of-the month inservice "guru". Stanovich and Stanovich further advocate that we stress and develop the commonalities between the world views of researchers and teachers:

Empiricism, broadly construed - as opposed to the caricature of scientists (white coats, numbers and test tubes) that is often used to discredit science - is about watching the world, manipulating it when possible, observing the outcomes, and trying to associate those outcomes with the features observed and with the manipulation. This is, of course, what the best teachers do. (p. 480)

While there is a grain of truth in the cliché "teaching is an art", the artistry can be enhanced by developing a closer relationship with science (Stanovich \& Stanovich, 1997). Alongside the creative, artistic element there should also be a systematic, hypothesis-setting, problem-solving approach to teaching.

\section{Support}

If we are not to remain locked in extant practices, shackled by what Malouf and Schiller (1995) refer to as "the arbitrary standards of practicality" (p. 422), we need not only a better understanding of the ecology of classrooms and the world views of teachers but also of the support that is needed to motivate and assist teachers to bring about change in their practice. Lenz et al. (1996) argue that intervention implementation "involves more than just the specification of an intervention plan. Consideration must be given to the process of supporting the intervention. It is the 'package' that must be of ultimate concern to the practitioner" (p. 120).

There is a large measure of consensus regarding the features of the supportive "package" (Deshler \& Schumacher, 1994; Gersten et al., 1997; Lenz et al., 1996; Nastasi \& Truscott, 2000; Nastasi et al., 2000; Pressley \& El-Dinary, 1997; Rosenfeld, 1991; Stanovich \& Stanovich, 
1997; Wong, 1997). Teachers are neither research subjects nor passive recipients of expertise, advice and instructions. It is necessary to engage them as equal partners, knowledge generators and co-constructors in the intervention process. Expanding the notion of acceptability beyond feasibility and consistency, with world views to include the involvement, empowerment and ownership of the teacher, helps teachers to "come to view the intervention as their own creation and take responsibility and control over the intervention process" (Nastasi et al., p. 208). Working in partnership, the key players together clarify the problem situation in the context of the ecology of the classroom, design the intervention in keeping with that ecology, implement it, monitor progress and evaluate its effectiveness - that is, they engage in joint problem solving.

Traditionally, interventionists (be they researchers or consultants) have favoured an expert role, controlling and directing prescribed strategies with a major focus on a pre-determined task to be implemented by the teacher (Bergan \& Kratochwill, 1990; Gutkin \& Curtis, 1999). The move to a collaborative approach emphasizes the communication strategies that facilitate shared responsibility (Wickstrom, Jones, LaFleur \& Witt, 1998; Gutkin \& Curtis,1999). In the expert model, the interventionist finds and prescribes a pre-designed intervention that the expert believes is appropriate. In the collaborative model, the interventionist works in partnership with the teacher to develop together an intervention of which the teacher will take ownership.

The latter model requires a much higher level of skill, requiring not just technical knowledge of, and competence in, empirically-based interventions but knowledge of how to use them strategically and skilfully. Skill and competence in communication and problem solving are essential. What is required is not strict adherence to a pre-designed programme but adaptation of that programme to fit the particular context in which the teacher is working. "The question for the interventionist becomes, 'What changes are needed in the intervention design to achieve an ecological niche for participants while preserving critical program elements?' [italics added]" (Nastasi et al., 2000, p. 214).

While the collaborative model requires a partnership of equals in a joint venture, the partners bring different but complementary expertise to the relationship. When teachers are expected to venture into new practices and try out new methods they need regular feedback from someone knowledgeable in the new strategies (Pugach \& Johnson, 1995). "Intense, frequent and substantive interaction is necessary" (Gersten et al., 1997, p. 470). Teachers need to be able to discuss, problem-solve, develop alternative strategies and be supported to merge research knowledge and the practice knowledge they bring to the partnership. They need to be given the opportunity to improve their skills in a safe environment - an important factor in increasing their self-efficacy and thus the likelihood of attempting new practices (Wong, 1997).

\section{Making "What Works" Work: Bridging the Research-Practice Gap}

In order to make "what works" work in practice, knowledge of empirically based interventions is not enough. Interventionists work with teachers to integrate theory and research into ecologically valid interventions in such a way that the teacher feels ownership and is empowered to implement them. This is no simple task, requiring not only technical and conceptual knowledge of interventions but also an in-depth understanding of schools, classrooms, teachers and how they function. What is needed to ensure "what works" works in classrooms is a network of scientist-practitioners with a range of both conceptual and practical skills. (Allen \& Graden, 1995; Nastasi et al., 2000; Stanovich \& Stanovich, 1997) who will provide a link between "the teacher at the front line and the theoretical generalizations of the university researcher" (Stanovich \& Stanovich, p. 478). These scientistpractitioners need the theory, research base and methodological rigour of the scientist, coupled with an understanding of the critical variables in the ecology of the classroom.

Here in New Zealand we have the potential to develop just such a cadre of scientist-practitioners - the Resource Teachers Learning and Behaviour (RTLB). They have a crucial role to play in supporting teachers to effect substantial change in practices in order to meet the serious challenges raised by recent reports (OECD, 2001; UNICEF, 2002).

SE 2000, the special education policy of the government (Ministry of Education, 1996), saw the establishment of 750 resource teachers whose role it is "to work with teachers ... to support positive outcomes for students" (Ministry of Education, 2001, s.1, p.1). Details of the history, role, function and training of RTLB have been outlined elsewhere (Glynn, 1998; Thomson et al., 2000; Thomson et al, 2003; 
Walker et al., 1999). The professional expectations of the RTLB by the Ministry of Education (2001), germane to the present discussion, are that they will have:

- An ecological approach to practice;

- Significant depth of knowledge in theory and practical application of effective practice;

- Skills in supporting teachers in effective programme implementation and adaptation;

- Skills in consultation, collaboration and facilitation;

- An approach to assessment and intervention incorporating databased decision making. [italics added]

The Ministry of Education contracted a consortium of three universities to devise and deliver training that would prepare RTLB to undertake the demanding role required by the new policy (Thomson et al., 2000; Thomson et al., 2003; Walker et al., 1999) and to be able to meet the expectations of their role as set out by the Ministry.

Because the RTLB are trained and experienced teachers, they enter the programme with a good understanding of teacher craft knowledge and a teacher's world view. The training builds on their experience but emphasizes the scientific aspects of teaching, assisting them to appreciate how theory and research guide assessment and intervention decisions; to follow a problem solving framework; to make decisions based on data; to treat intervention choices as testable hypotheses and in general to value and practise methodological rigour.

In the course of their training, many of the RTLB move from seeing their role as fixing up, or assisting the teacher to fix up, deficits in students, to assisting the teacher to identify and manipulate the critical environmental variables for improving teaching and learning. The RTLB come to embrace an ecological/interactionist perspective that is appropriate to their role.

Emphasis is placed on learning how to adapt the classroom programme to meet the needs of particular students. The classroom programme is the starting point, and RTLB first look to develop strategies that are the least intrusive. They are trained to be highly skilful in methodologies and strategies such as cooperative learning, peer tutoring and reciprocal teaching, which are known to have a high level of acceptability to teachers because they benefit all students and not only those identified as having special needs.
Underpinning all the strands in the training programme is the notion of collaboration with the teacher. RTLB are taught to eschew an expert model and embrace one of partnership with the teacher. This is much more than developing a "feel good" approach of supporting and encouraging. Support and encouragement are necessary but not enough. Much more is required of successful resource teachers. Interpersonal communication and facilitation skills need to be developed to a high level of competence. RTLB are required to bring the strands of their professional development programme together in a cooperative partnership with the teacher, working within a problem-solving framework, from ecologically-derived assessment data, in order to adapt sound theory and research into the classroom environment to bring about better outcomes for students. Figure 1 is taken from material used in the programme to clarify the training approach taken to the RTLB role (Thomson, 2000).

\section{A CONTEXT OF COLLABORATION}

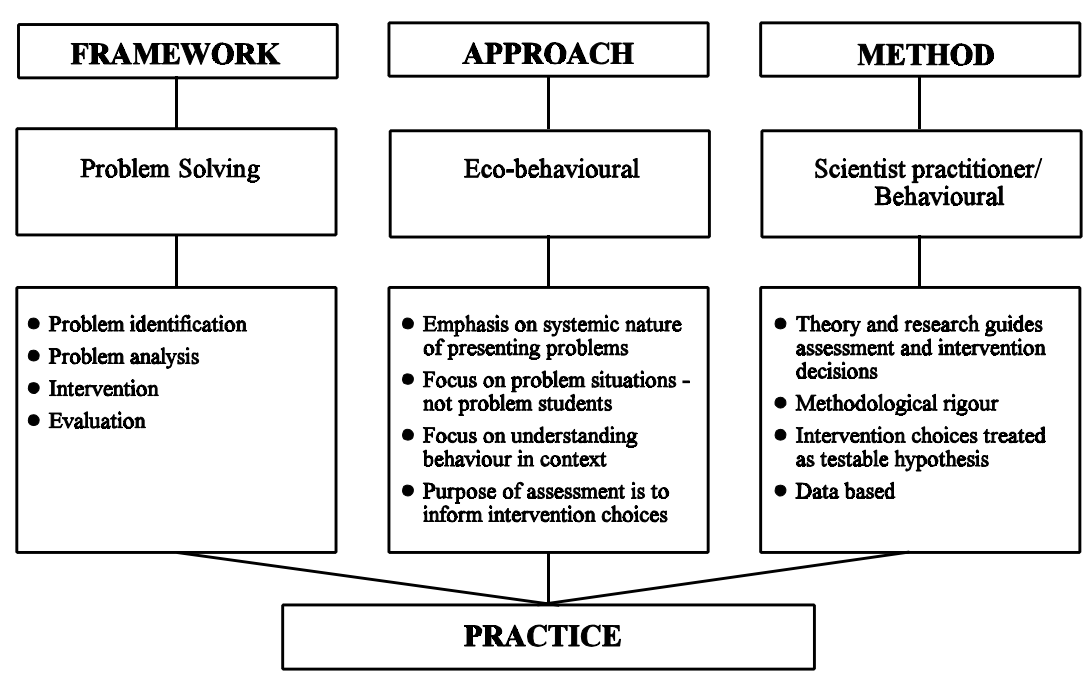

Figure 1 The Role of the RTLB 
The RTLB training programme and the role and expectations as outlined by the Ministry in the RTLB handbook (Ministry of Education, 2001) are in complete accord. Both illustrate what is required of scientist-practitioners who would intervene to introduce empirically based strategies into the classroom. We have a group of resource teachers trained in what the literature tells us helps to make "what works" work.

\section{Conclusion}

Despite the rhetoric over improving educational outcomes, little seems to change. The New Zealand record of rates of failure to "graduate" from secondary education with appropriate qualifications is still a matter for deep concern. Despite the urging of researchers, teachers continue to ignore or remain distanced from knowledge and behaviours that offer some promise for improvement.

Reviewing his research career, Ysseldyke (2001), somewhat pessimistically, concludes, "Change is difficult. Change that involves extra work is next to impossible" (p. 300). When one adds into the equation that the person who is required to do the changing (the teacher) is not the person who is going to benefit most from the change (the student) then one has cause to be even more pessimistic. However, we tend to adjust to small incremental changes, so that sometimes we do not notice the progress actually being made. This author, reviewing her career as a field practitioner and a tertiary educator, tends to a more optimistic view. For example, in the late seventies, when she started as a field psychologist, all children with Downs syndrome were either institutionalized or educated in segregated special schools. No one would suggest now, as happened then, that such a child should be institutionalized at birth. Indeed, now almost all children with Downs syndrome are integrated, if not fully included, into mainstream schools. Subsequently they are being employed and living in the community. Attitudes have changed; new skills have been learnt and applied. We have made progress. It has just taken time.

The proposition I have put forward here is that for change to occur in our work with learners who are struggling, and being failed by the system, teachers need support from highly skilled resource teachers who understand the process of collegial collaborative problem-solving. These resource teachers also require knowledge about empirically based practices and skillsin effectively translating that information into classroom action. I suggest that one way to achieve such a goal is through skilled consultation that taps into the notion of intervention acceptability, and then extends into consistent practice. There may well be other approaches that might be equally successful. I would welcome them. In the meantime, the literature supports the proposition that only with a significant change in our approach are we likely to make inroads into changing what is becoming a national embarrassment.

Certainly, teacher preparation to follow a more scientistpractitioner model needs to be considered. School organization, which takes account of fundamental principles of effective education, needs to be addressed. The thesis of this article is that classroom teachers play a pivotal role in determining who succeeds and who fails in school. Without intensive support, these teachers will continue to do what they are doing now, and we shall continue to get the results we are getting now. Focused, intensive support for teachers of students who struggle and/or fail is needed now. I believe the RTLB are a cadre of resource personnel who can meet this need, provided they continue to practice in the manner in which they have been trained, provided also that school leaders and administrators ensure such practice is facilitated in every school and for every teacher who needs such support.

\section{References}

Allen, S. J., \& Graden, J. L. (1995). Best practices in collaborative problem solving for intervention design. In A. Thomas \& J. Grimes (Eds.), Best practices in school psychology III (pp. 667-678). Washington: National Association of School Psychologists.

Alton-Lee, A. (2003). Quality teaching for diverse students in schooling: Best evidence synthesis. Wellington: Ministry of Education.

Bergan, J. R., \& Kratochwill, T. R. (1990). Behavioural consultation and therapy. New York: Plenum Press.

Carnine, D. (1995). Trustworthiness, usability, and accessibility of educational research. Journal of Behavioural Education, 5, 251-258.

Department of Education. (1988). Tomorrow's schools: The reform of educational administration in New Zealand. Wellington: Government Printer. 
Deshler, D. D., \& Schumaker, J. B. (1994). Grounding intervention research in the larger context of schooling: A response to Pressley and Harris. Educational Psychology Review, 6(3), 215-222.

Detrich, R. (1999). Increasing treatment fidelity by matching interventions to contextual variables within the educational setting. School Psychology Review, 48(4), 608-621.

Eckert, T. L., \& Hintze, J. M. (2000). Behavioural conceptions and applications of acceptability: Issues related to service delivery and research methodology. School Psychology Quarterly, 15(2), 123-148.

Education Review Office. (1998, Autumn). Working with students with special abilities. Report No. 3. Wellington: ERO.

Elliott, S. N., \& Darveaux, D. X. (1985). Teacher judgments concerning the acceptability of school-based interventions. Professional Psychology: Research and Practice, 16(2), 191-198.

Elliott, S. N., Witt, J. C., \& Kratochwill, T. R. (1991). Selecting, implementing and evaluating classroom interventions. In $\mathrm{G}$. Stoner, M. R. Shine, \& H. M. Walker (Eds.), Interventions for achievement and behaviour problems (pp.99-135). Silver Springs, MD: National Association of School Psychologists.

Forness, S. R., Kavale, K. A., Blum, I. M., Lloyd, J. W. (1997). Analysis of mega-analysis: What works in special education and related services? Teaching Exceptional Children, 29(6), 4-9.

Fullan, M. G. (1991). The new meaning of educational change. New York: Teachers College Record.

Gersten, R., \& Brengelman, S. U. (1996). The quest to translate research into classroom practice: The emerging knowledge base. Remedial and Special Education, 17(2), 67-74.

Gersten, R., Vaughn, S., Deshler, D., \& Schiller, E. (1997). What we know about using research findings: Implications for improving special education practice. Journal of Learning Disabilities, 30(5), 466-476.

Glynn, T. (1998, July). A collaborative approach to teacher development: New initiatives in special education. Paper presented at the 28th Annual Conference, Australian Teacher Education Association, Melbourne.

Gresham, F. M. (1989). Assessment of treatment integrity in school consultation and prereferral intervention. School Psychology Review, 18(1), 37-50.
Gresham, F. M., \& Lopez, M. F. (1996). Social validation: A unifying concept for school-based consultation research and practice. School Psychology Quarterly, 11(2), 204-227.

Gutkin, T. B., \& Curtis, M. J. (1999). School based consultation theory and practice : The art and science of indirect service delivery. In C. R. Reynolds \& T. B. Gutkin (Eds.), The handbook of school psychology (3rd ed.) (pp. 598-637). New York: John Wiley \& Sons, Inc.

Kazdin, A. E. (1981). Acceptability of child treatment techniques: The influence of treatment efficacy and adverse side effects. Behaviour Therapy, 12, 493-506.

Kratochwill, T. R., \& Stoiber, K. C., (2000). Empirically supported interventions and school psychology: Conceptual and practice issues. Part II. School Psychology Quarterly, 15(2), 233-254.

Lenz, F. E., Allen, S. J., \& Ehrhardt, K. E. (1996). The conceptual elements of strong interventions in school settings. School Psychology Quarterly, 11(2), 118-136.

Lenz, F. E., \& Daly, E. J. (1996). Is the behaviour of academic change agents controlled metaphysically? An analysis of the behaviour of those who change behaviour. School Psychology Quarterly, 11(4), 337-352.

Malouf, D. B. \& Schiller, E. P. (1995). Practice and research in special education. Exceptional Children, 61(5), 414-425.

Ministry of Education. (1993). The New Zealand Curriculum Framework. Wellington: Learning Media.

Ministry of Education. (1994). Schooling in New Zealand: A guide. Wellington: Ministry of Education.

Ministry of Education. (1996). Special Education 2000. Wellington: Ministry of Education.

Ministry of Education. (1997). Governing and managing New Zealand schools: A guide for boards of trustees. Part one: The National Education Guidelines. Wellington: Learning Media.

Ministry of Education. (2001). Resource teachers learning and behaviour clusters: Effective governance, management and practice. Wellington: Ministry of Education, Special Education Unit.

Ministry of Education. (2004). School leavers (2002). Statistical tables on school leavers in 2002. Retrieved January 26, 2004 from <www.minedu.govt.nz/Schools/SchoolStatistics/Results for 2002> 
Nastasi, B. K., \& Truscott, S. D. (2000). Acceptability research in school psychology: Current trends and future directions. School Psychology Quarterly, 15(2), 117-123.

Nastasi, B. K., Varjas, K., Schensul, S. L., Silva, K. T. (2000). The participatory intervention model: A framework for conceptualizing and promoting intervention acceptability. School Psychology Quarterly, 15(2), 207-233.

OECD. (2001). Knowledge and skills for life: First results from PISA 2000. Paris: OECD

Pressley, M., \& El-Dinary, P. B. (1997). What we know about translating comprehension-strategies instruction research into practice. Journal of Learning Disabilities, 30(5), 486-488.

Pugach, M. C., \& Johnson, L. J. (1995). Unlocking expertise among classroom teachers through structured dialogue: Extending research on peer collaboration. Exceptional Children, 62(2), 101-110.

Richardson, V. (1990). Significant and worthwhile change in teaching practice. Educational Researcher, 23(5), 5-10.

Rosenfeld, S. (1991). The relationship variable in behavioural consultation. Journal of Behavioural Education, 1(3), 329-336.

Scott, B., Vitale, M. R., Masten, W. G. (1998). Implementing instructional adaptations for students with disabilities in the inclusive classroom: A literature review. Remedial and Special Education, 19(2), 106-119.

Shulman, L. S. (1998). Theory, practice and the education of professionals. The Elementary School Journal, 98(5), 511-526.

Schumm, J. S., Vaughn, S., Haager, D., McDowell, J., Rothlein, L., \& Saumell, L. (1995). General education teacher planning: What can students with learning difficulties expect? Exceptional Children, 61(4), 335-352.

Stahl, S. A. (1999. Different strokes for different folks? A critique of learning styles. American Educator, 23(3), 27-31.

Stanovich, P. J., \& Stanovich, K. E. (1997). Research into practice in special education. Journal of Learning Disabilities, 30(5), 477-481.

Stoiber, C. K., \& Kratochwill, T. R. (2000). Empirically supported interventions and school psychology: Rationale and methodological issues. Part I. School Psychology Quarterly, 15(1), 75-106.
Swanson, H. L. (2001). Searching for the best model for instructing students with learning disabilities. Focus on Exceptional Children, 34(2), 1-14.

Telzrow, C. F. \& Beebe, J. J. (2002). Best practices in facilitating intervention adherence and integrity. In A. Thomas \& J. Grimes (Eds.), Best practices in school psychology IV (pp. 503-516). Bethesda, MD: The National Association of School Psychologists.

Thomson, C. (2000). The role of the RTLB. RTLB programme: Unpublished lecture notes. Universities Consortium.

Thomson, C., Brown, D., Jones, L., \& Manins, E. (2000). The development of resource teachers in New Zealand: A quarter century of paradigm change. New Zealand Annual Review of Education, 9, 23-42.

Thomson, C., Brown, D., Jones, L., Walker, J., Moore, D. W., Anderson, A. et al. (2003). Resource teachers learning and behaviour: Collaborative problem solving to support inclusion. Journal of Positive Behaviour Interventions, 5(2), 101-111.

UNICEF. (2002, November). A league table of educational disadvantage in rich nations. Innocenti Report Card 4. Florence, Italy: UNICEF Innocenti Research Centre.

Vaughn, S., Klinger, J., \& Hughes, M. (2000). Sustainability of researchbased practices. Exceptional Children, 66(2), 163-172.

Walker, J., Moore, D. W., Anderson, A., Brown, D., Thomson, C., Glynn, T. et al. (1999). Innovative inclusion initiative: The resource teachers learning and behaviour programme. Paper presented at the AARE-NZARE Conference, Melbourne, Australia.

Wickstrom, K. F., Jones, K. M., LaFleur, L. H., Witt, J. C. (1998). An analysis of treatment integrity in school-based behavioural consultation. School Psychology Quarterly, 13(2), 141-151.

Witt, J. C., \& Elliott, S. N. (1985). Acceptability of classroom intervention strategies. In T. R. Kratochwill (Ed.), Advances in school psychology, Vol. 4 (pp. 251-288). Hillsdale, NJ: Erlbaum.

Wolf, M. M. (1978). Social validity: The case for subjective measurement of how applied behaviour analysis is finding its heart. Journal of Applied Behaviour Analysis, 11, 203-214. 
Wong, B. Y. L. (1997). Clearing hurdles in teacher adoption and sustained use of research-based instruction. Journal of Learning Disabilities, 30(5), 482-485.

Ysseldyke, J. (2001). Reflections on a research career: Generalizations from 25 years of research on assessment and instructional decision making. Exceptional Children, 67(3), 295-309.

\section{The author}

Charlotte Thomson, previously a teacher, psychologist and Director of School of Special Education at Wellington College of Education, is at present a senior lecturer on the RTLB professional development programme at Victoria University of Wellington. Since 1990 she has worked principally as a teacher educator and consultant to schools. Her main research interest is collaborative problem solving and the cooperative partnership between teachers and resource teachers. 